\title{
LA ESCRITURA ENTRE LA ANTROPOLOGÍA Y LA LITERATURA EN JOSÉ MARÍA ARGUEDAS*
}

\author{
Rômulo Monte Alto*
}

Resumen: Este texto trata de las relaciones entre la escritura literaria y antropológica en José María Arguedas, desde el examen de parte de sut correspondencia con antropólogos, asi como de sus textos ficcionales, especialmente, su última novela $\mathrm{El}$ zorro de arriba y el zorro de abajo (1971).

"Por otra parte creo que serás un antropólogo. $\mathrm{Me}$ acuerdo con felicidad infantil cómo me preguntaste cierto día, en el Museo de la Cultura, si no había incompatibilidad entre el arte y la antropología, entre el saber artístico y la ciencia. $Y$ yo te dije que había mucha necesidad de ambas cosas pero que no era fácil que alguien tuviera condiciones para lograrlo." (RESCANIERE, 1996, p. 265)

* Recebido para publicação em maio de 2007.

** Professor da Faculdade de Letras/UFMG 
Al escribir esta carta al joven estudiante Alejandro Ortiz Rescaniere, que se encontraba en París realizando sus estudios de posgrado en Antropología con Lewi-Strauss, José María Arguedas se refería a una relación no del todo esclarecida dentro del universo de la trasdiciplinaridad: se trata de las relaciones entre arte y ciencia, configuradas en el cruce de lo literario y lo antropológico. El profesor y crítico literario Martin Lienhard, en entrevista a Roberto Ventura, publicada en el Suplemento mais!, del diario Folha de São Paulo, comenta sobre la "antropologização da literatura":

"Há, na literatura da América Latina, uma relação muito forte com a antropologia, porque houve nas colônias, desde a conquista e a colonização, um poder metropolitano representado por funcionários civis e eclesiásticos que governavam uma população formada por imigrantes de origem européia, pelos índios que eram o grupo majoritário e pelos africanos com seus descendentes. Os escritores latino-americanos se viram frente ao problema de saber como era possível a coexistência de grupos tão diferentes. A antropologização da literatura foi assim uma constante na América Latina." (LIENHARD, 1998 , p. 12)

El objetivo de este ensayo es investigar algo de esa imbricada relación en algunos escritos, cartas y palabras del escritor y antropólogo peruano José María Arguedas, especialmente en su última novela El zorro de arriba y el zorro de abajo, partiendo del supuesto de que la antropología, como ciencia que motiva una escritura específica - los "textos 
motivados", como afirma Roberto DaMatta (DAMATTA, 1993, p. 40) - informará también a la literatura, pero resultará, por su turno, deformada o cambiada por una serie de exigencias que la misma literatura impone desde su singularidad. Dicho de otro modo, las preguntas que plantea un antropólogo y que dan partida a una investigación etnográfica, y que de alguna manera suponen una respuesta que se busca ver confirmada, no encontrarán en los dominios de la literatura los mismos vínculos de expectativas y trámites de interrelación. Que esa "deformación de los bordes" es algo que ocurre en las vencidades de los campos interdisciplinarios, cuando dos o más disciplinas están en pleno roce, se espera; lo distinto en el caso de nuestro escritor-antropólogo es que su actividad literaria señala hacia una reubicación de las preguntas y de los conceptos, además del propio lugar de la antropología, y por ende de la ciencia, en el heterogéneo universo latinoamericano.

En la larga y proficua correspondencia que sostuvo con Rescaniere, hijo de su amigo José Ortiz Reyes, quien inicialmente era su correspondiente, Arguedas planteaba su condición de investigador social ("Yo soy antropólogo", decía), un estudioso de las sociedades en las que había vivido y seguía viviendo. Compartía con Alejandro la certeza de "la antropología como una nueva disciplina que sirve para entender mejor el mundo en el que vivimos" (RESCANIERE, 1996, p. 220), la otra cara del mismo pensamiento que llevó John Murra a afirmar, en el prólogo al libro también de correspondencias que mantuvo con José María, que la arqueología se benefició del interés de los Estados Unidos hacia el continente sudamericano durante la Segunda Guerra arácte (MURRA y LÓPEZ-BARALT, 1996). Es decir, desde una base o matriz positivista que veía la antropología como una 
de las herramientas de la ciencia a arácters de las sociedades y de los individuos para su arácter material y arácter; un saber autorizado por una metodología, confirmado en los experimentos y avalado por una teoría que describía los fenómenos observados. Le escapó a Murra el hecho de que toda arácters es una construcción discursiva y por lo tanto responde a las arácters del sujeto que describe, no estando así exenta de un cierto nivel de interferencias por parte de ese sujeto. Desde ese ángulo se comprende mejor la asertiva, pues hay que recordar que durante la Segunda Guerra arácte se está engendrando el dualismo que la Guerra Fría brindará a la humanidad en los próximos 40 años; aparte de eso, hay que añadir lo que significaron los estudios de área para la presencia y hegemonía americana en América Latina, tema que ha sido deslindado por Alberto Moreiras en $A$ exaustão da arácter (Editora ará, 2001) y los estudios poscoloniales de modo más amplio. No que de hecho Murra pensara así por gusto o intención, sino más bien que refleja una manera de pensar corriente entre los antropólogos en aquella época.

Arguedas veía la antropología como una tarea trascendental a ser llevada a cabo y afirmaba en ella su arácter casi religioso:

"A la cultura la están aniquilando o tratando de aniquilar planificadamente y creo que con el propio auxilio de de un equipo de pseudoetnólogos. El trabajo que tienes que realizar es pues no sólo interesantísimo, fuente de la más grande dicha, sino que tendrá algunos visos de heroico y de misional. Un poco como lo que hizo Ávila, pero al revés." (RESCANIERE, 1996, p. 243) 
Francisco de Ávila, un cura que vivió en el siglo XVI y fue considerado un "extirpador de idolatrías", recogía mitos y leyendas de las culturas indias con el fin de probar su afinidades satánicas y con eso, destinarlas al exterminio. El celo con que el famoso cura realizaba su labor es evocado por Arguedas como ejemplo de devoción, pero en sentido totalmente contrario. En otra carta, esta vez a Murra, resalta el error de los que "consideran la etnología como una ociosa descripción de costumbres" (MURRA y LÓPEZ-BARALT, 1996, p. 47), en una alusión al progreso de los conceptos y de la práctica etnográfica. Ésta no debería restringirse a descripciones de pequeñas y lejanas comunidades, sino que debería ponerse a servicio de los cambios que afectan a los individuos y comunidades como un todo. Murra, en cambio, se refiere al "tratamiento o acercamiento antropológico" en las novelas de Arguedas: "Sus obras de alguna manera tratan de los cambios acelerados. Aun antes de ser antropólogo y de estudiar formalmente el asunto, tenía tal preocupación." (MURRA y LÓPEZ-BARALT, 1996, p. 192) Durante el XXXVII Congreso de Americanistas, realizado en la ciudad de La Plata en 1966, en que se discutía el rol que le cabía a la antropología frente a las culturas amenazadas por la avanzada penetración de la cultura occidental, Arguedas sostenía que "la llamada antropología de urgencia no podía tener un objetivo limitado al registro." (ARGUEDAS, 1977, p. 184) Queda claro para el antropólogo peruano el carácter urgencial y salvífico que se le confiere a la antropología en la lucha por la preservación de las culturas dichas primitivas.

Pero lo que diferencia Arguedas de los demás antropólogos escritores es su ubicación respecto de la(s) cultura(s) en que está inmerso: como vivió entre los indígenas cuando era niño, aprendió a hablar el quechua antes que el 
español, hecho que definió los marcos de su vida personal y su labor profesional, y lo llevó a vivir desde entonces en una región fronteriza a las dos culturas. En el discurso pronunciado al recibir el premio Garcilaso de la Vega, reitera su condición de extraño en la ciudad y su resistencia a la cultura occidental con la conocida frase: "No soy un aculturado". Rescaniere, en una carta de diciembre de 67, le exhorta a "aceptar sus privilegios" por vivir en el entre-lugar que le tocaba:

"Tú conoces esa cultura de fuera y de dentro, yo sólo de fuera y a medias. Conocer una cosa de fuera da objetividad y se es así y, sólo así, verdadero etnólogo; pero tú, aparte de ser capaz de ser etnólogo; es decir, hombre de ciencia occidental que estudia una cultura exótica, tú puedes, además, vivirla, pensar en esa cultura: tu privilegio es único: es como si Lévi-Strauss pudiera, para ir al campo, dejar de ser francés, de pensar en occidental y poder pensar en bororo, $y$ luego, a semivoluntad, volver a ser francés. ¿Te das cuenta qué maravilla? El J. María etnólogo puede estudiar al informante José María. Es casi imposible de imaginar. Pero basta leer Los Ríos Profundos para saber que tal fenómeno existe. Los cholos rechazan una de sus culturas, es raro la persona que acepte consciente o inconscientemente ser dos cosas a la vez, hay que tener coraje, suerte, mucha suerte, y capacidad para poder aceptar una situación tan extraña." (RESCANIERE, 1996, p. 245-246) 
El privilegio de que disfruta Arguedas, el de ser informante e informado al mismo tiempo, influye sobremanera en su obra, sea la antropológica, sea la literaria. El extenso artículo que publicó en la Revista del Museo Nacional bajo el título "Evolución de las Comunidades Indígenas", empieza con el relato del encuentro entre Pizarro y la nobleza Inca cuzqueña, desde una perspectiva histórica que se adueña de textos recogidos por cronistas que acompañaban a los conquistadores, textos en los cualesseencuentran descripciones de la zona, los indios y las condiciones de vida de entonces. En otro ensayo antropológico, "Puquio, una cultura en proceso de cambio", publicado en Formación de una cultura nacional indoamericana, se encuentra la transcripción en quechua de las tres versiones que Arguedas descubrió del mito de Inkarrí en la zona de Puquio, seguidos de la traducción al español, estilo de narrativa que encuentra similares en algunas novelas del escritor, principalmente en El zorro de arriba y el zorro de abajo.

Por fin, desde esa perspectiva vale recordar el proyecto al cual se dedicó Arguedas, juntamente con Rescaniere, en los últimos meses de vida de que disponía: la creación de un Laboratorio de Mitología Andina, que se dedicaría a la recogida y estudio de los mitos pre y poshispánicos. Al proponer que "el Laboratorio de Mitología Andina llegaría con el tiempo a ser un Laboratorio de Mitología, en el cual se estudiarían los mitos del mundo entero, tomando como referencia la andina" (RESCANIERE, 1996, p. 291), el proyecto anticipaba el desplazamiento que, décadas más tarde, Walter Mignolo, desde los umbrales de la poscolonialidad latinoamericana, planteaba como necesario para la construcción de un "decir arraigado": "...esnecesario un pensara partir delas ruinas andinas y mesoamericanas, de la misma manera que el pensamiento europeo construyó un relato coherente a partir de las ruinas del pasado greco-romano." (MIGNOLO, 1995, p. 27) 
La escritura antropológica se caracterizó, en sus comienzos, por constituirse como relatos de viajes, que viajeros, artistas y estudiosos de los países centrales realizaban para conocer las culturas "exóticas", o sea, las que no se situaban en el perímetro central del mundo occidental. Si leemos la obra de Arguedas desde las lentes de la migración, lectura propuesta por Antonio Cornejo Polar en su texto "Condición migrante e intertextualidad multicultural" (CORNEJO POLAR, 1997, p. 267-279), podemos describirla como el relato de un viaje que emprende la inmensa masa de serranos (indios y mestizos) que migran hacia las metrópolis urbanas, precisamente Lima, la capital. El crítico uruguayo Ángel Rama también ya lo advertía, cuando se refería a las "progresivas ampliaciones" que operaba Arguedas en su obra, así como los cambios y la evolución de su pensamiento desde sus primeras novelas (ARGUEDAS, 1997, p. XIII). Ya Julio Noriega, al profundizar el análisis desde ese punto de vista, nombra a Arguedas "el fundador de la poética quechua migrante", una vez que con su libro Canto Kechwa, editado en 1938, abre las puertas de la capital a la cultura andina e inaugura una nueva recepción estética para las obras que provienen de esa cultura. El propio escritor estaría a la cabeza de ese viaje de "reconquista mítica" que, de acuerdo a Noriega, los serranos emprenden hacia la ciudad letrada, pues su trayectoria es la misma de la sus paisanos (NORIEGA, 1996, p. 311-338). De ahí que la obra de Arguedas pueda también ser leída e interpretada como un relato de viaje, desde una perspectiva antropológica, lo que no invalida ni tampoco disminuye su carácter literario.

En su última novela, El zorro de arriba y el zorro de abajo, Arguedas se vale del vasto material que recogió en la ciudad costeña de Chimbote, durante los varios viajes que hizo hacia allá, con el intento inicial de llevar a cabo un estudio 
antropológico de naturaleza folclórica. Tras entrar en contacto con la realidad a través de entrevistas que realizó con obreros fijos y eventuales, capitanes de bolicheras, indios recién llegados, jefes de plantas industriales, entre otros, decide cambiar de idea; algunas de estas entrevistas se puede leer al final de la edición crítica de El zorro... que organizó Eve-Marie Fell. En el informe $\mathrm{n}^{\circ} 1$, dirigido a la Universidad Agraria, donde expone los motivos por que ha elegido Chimbote (por razones de salud inicialmente, nada más), se puede leer en su justificativa para el denominado "Proyecto de Estudio en Chimbote sobre Migraciones y Relaciones entre la Población de la Sierra y de la Costa":

"Pero me encontré con que la ciudad de Chimbote es una especie de gran remolino social en el que grupos emigrados de diferentes zonas de la costa y de la sierra han entablado un estado de relaciones especialísimas, determinadas, al parecer, fundamentalmente por sus diferentes formaciones culturales. [...] Informé a ambas autoridades académicas sobre los primeros resultados de mi trabajo entre los cuales se tuvo en cuenta la entrevista grabada que hice a un patrón de lancha puneño, procedente de Yunguyo y que había sido analfabeto aymara hasta los treinta años. En este documento podía conocerse el grado de tensión que existe en la población de Chimbote, entre serranos y costeños. Propuse estudiar, principalmente, este fenómeno que es importante para nuestro mejor conocimiento de la actual realidad social del país y de los factores que la han determinado." (ARGUEDAS, 1996, p. 385) 
La narrativa de El zorro... se construye desde el interior de esos relatos antropológicos, Io que le confiere al texto características de una moderna etnografía urbana. Del jefe de lancha Chaucato al loco Moncada, el autor describe un sin fin de tipos raros, creando un mosaico humano cuyo objetivo es representar la diversidad de aquella formación social. El tema de la representación es una obsesión para Arguedas y lo planteó de una manera más clara en el Primer Encuentro de Narradores Peruanos, que tuvo lugar en Arequipa, en 1965. El comentario de haber estado en Chimbote se puede leer en los Diarios, en que Arguedas, además de discutir sobre los personajes sobre los cuales acaba de escribir, afirma la estrechez de los límites entre lo ficcional y lo real:

"Voy a atenacear o aburrir a los posibles lectores de esta posible novela, interrumpiéndola nuevamente con un diario, porque estoy otra vez en el pozo, con el ánimo en casi la nada. Luego de haber escrito el capítulo III en el que creo que puede encauzar el espacio abierto, como de un redondo y algo aturdido hormiguero de hombres y destinos que es el segundo capítulo; luego de haber presentado confidencialmente a mis amigos don Esteban de la Cruz y el loco Moncada en el capítuo IV, y cuando me faltaban sólo unas páginas para concluir ese capítulo, decidí llamar a mi mujer a Arequipa, para celebrar la salida del pozo, de la brea que amargaba mi pensamiento." (ARGUEDAS, 1996, p. 173) 
Al borrar los límites entre realidad y ficción, Arguedas acaba por tornar fluidas las fronteras entre literatura $y$ antropología en el ámbito de la novela, algo que ya ocurría en otras novelas anteriores como El Sexto y Todas las Sangres. El sentido lo encontramos en la inversión que efectúa Arguedas en la práctica antropológica de la época: ya no se trata de hacer antropología "desde" la ciudad (realizando descripciones etnográficas de pequeñas comunidades tradicionales), sino "en" la ciudad. Frente a los cambios radicales que la modernización del país impuso a sus habitantes (serranos o costeños) cuyo resultado más évidente fue la masiva migración interna en dirección a la ciudad, con la consecuente disgregación cultural e identitaria que acompaña tales procesos, la antropología se da cuenta de la necesidad de estudiar esas nuevas formaciones culturales que se están erigiendo en los núcleos urbanos. Para eso necesita penetrar, conocer, pasearse por los rincones de esa ciudad desconocida que está cambiando de diseño y de forma rápidamente. Arguedas cumple de esa manera el pronóstico que, años más tarde, Néstor García Canclini predice para la antropología de "que el papel principal de los antropólogos en ese fin de siglo latinoamericano sea el de críticos de la modernidad." (CANCLINI, 1994, p. 114) El planteo de Canclini se inscribe dentro del universo contradictorio que engendró la pseudo-modernización ocurrida en el continente y se funda en la esperanza de que la antropología ayude a "complejizar" el debate que en la actualidad el neoliberalismo intenta simplificar. Al describir sus personajes dándoles voz y valor, al enlazar literatura y antropología bajo el mismo trazado descriptivo, al dejar atrás los "temas de la infancia", supuesta referencia al indigenismo en que estuvo inmerso con los primeros escritos, Arguedas también concreta otro deseo 
de Canclini: "Uno queda con ganas de que esa imaginativa labor desmitificadora fuera acompañada, como corresponde a una investigación antropológica, por una etnografía de las representaciones de las identidades actuantes en las interacciones cotidianas." (CANCLINI, 1994, p. 117)

Finalmente, el mayor aporte de la antropología presente en $E l$ zorro... lo encontramos en la estructura de la novela, cuyo eje se orienta en torno a la presencia de dos zorros mitológicos, recogidos del relato de Francisco de Ávila hacia 1598 y recopilado por el mismo Arguedas en 1966, titulado Dioses y hombres de Huarochiri. El cruce entre biografía, novela y mito ha sido analizado por Cornejo Polar que planteó los tres niveles que se entrecruzan en el enredo: "Pero El zorro... no se estructura mediante la alternancia de autobiografía y novela, también incluye, con jerarquía funcional paralela a la de los dos niveles anteriores, un discurso estrictamente mágico."(CORNEJO POLAR, 1997, p. 232) Ya Martin Lienhard encuentra que "la irrupción de lo mitológico en esta novela es consecuencia de las relaciones que existen entre este texto y un universo mitológico concreto, el de los campesinos andinos anteriores o posteriores a la conquista española."(LIENHARD, 1981, p. 85) Según Lienhard, Arguedas al apropiarse de los mitos para construir su relato, quiere contraponer al mito capitalista de la felicidad, representada y sostenida por la naciente industria de la harina de pescado de Chimbote, los antiguos mitos colectivos que los serranos, ahora sumergidos en cruel realidad de la ciudad, ya empiezan a olvidar. Al poner en relieve la actualidad de los mitos en la sociedad contemporánea, la antropología nos enseña que, lejos de creer en su desaparición, los mitos siguen ocupando lugar de preeminencia en la sociedad. Por fin al narrar su muerte real como un proyecto ficcional cuyo remate desborda las páginas 
finales de la novela, el escritor peruano trenza los hilos de los discursos literarios y antropológicos en torno a su cuerpo, que deja de ser simultáneamente informante e informado para volverse un incómodo y misterioso objeto de investigación sobre as relaciones que los dos campos disciplinarios plantean entre sí, especialmente después que saber que el escritor, una vez lanzada la consigna del suicidio, ya no sería capaz de retroceder frente a las exigencias del antropólogo.

Resumo: Este texto trata das relações entre a escrita literária e a antropológica em José María Arguedas, a partir do exame de parte de sua correspondência com antropólogos, bem como de seus textos ficcionais, especialmente, seu último romance El zorro de arriba y el zorro de abajo (1971).

\section{Referencias:}

ARGUEDAS, José María. El zorro de arriba y el zorro de abajo. Edición crítica de Eve-Marie Fell, Colección Archivos. Madrid: Fondo de Cultura Económico/Allca XX, 1996.

- Formación de una cultura nacional indoamericana. México: Siglo Veintiuno Editores, 1977.

. Evolución de las Comunidades Indígenas. Revista del Museo Nacional, Lima, 1957, p. 23-34.

CANCLINI, Néstor García. Los estudios culturales de los 80 a los 90: perspectivas antropológicas y sociológicas en América Latina. Posmodernidad en la periferia. Hermann Herlinghaus y Monika Walter (Editores). Berlin: Langer, 1994.

CORNEJO POLAR, Antonio. El zorro de arriba y el zorro de abajo. Palabra y realidad. Los universos narrativos de José María Arguedas. Lima: Editorial Horizonte, 1997.

DAMATTA, Roberto. Conta de mentiroso: sete ensaios de antropologia brasileira. Rio de Janeiro: Rocco, 1993.

FOUCAULT, Michel. Las palabras y las cosas. Una arqueología 
de las ciencias humanas. Madri: Siglo Veintiuno Editores, 1997. LIENHARD, Martin. Cultura andina y forma novelesca: zorros y danzantes en la última novela de Arguedas. Lima: Editorial Horizonte/Tarea, 1990.

LIENHARD, Martin. A antropologização da literatura. Entrevista a Roberto Ventura. F. de São Paulo, Suplemento MAIS!, 13 de dezembro de 1998. (Internet: http://www1. folha.uol.com.br/fsp/mais/fs13129 812.htm)

MAZZOTTI, José Antonio; AGUILAR, U. Juan Zevallos (Coordinadores). Asedios a la heterogeneidad cultural. Philadelphia: Asociación Internacional de Peruanistás, 1996.

MIGNOLO, Walter. Decires fuera de lugar: sujetos dicentes, roles sociales y formas de inscripción. Revista de Crítica Literaria Latinoamericana, año XXI, no. 41, Lima-Berkeley, 1er. semestre de 1995, p. 9-31.

MURRA, John V. y LÓPEZ-BARALT, Mercedes. Las Cartas de Arguedas. Lima: Fondo Editorial de la Pontificia Universidad Católica del Perú, 1996.

NORIEGA, Julio. La poética quechua del migrante andino. In: Asedios a la heterogeneidad cultural. José Antonio Mazzoti e Ulises Juan Zevallos Aguilar (coordenadores). Philadelphia: Asociación Internacional de Peruanistas, 1996.

POLAR, Antonio Cornejo. Los universos narrativos de José María Arguedas. Lima: Editorial Horizonte, 1997.

Primer Encuentro de Narradores Peruanos. Arequipa, 1965. Lima: Latinoamericana Editores, 1969.

RESCANIERE, Alejandro Ortiz. José María Arguedas, recuerdos de una amistad. Lima: Fondo Editorial de la Pontificia Universidad Católica del Perú, 1996.

REVISTA DEL MUSEO NACIONAL, Lima-Perú, tomo XXVI, 1957, p. 78-151. 